\title{
Epidermal growth factor receptor (EGFR) gene promoter methylation and cetuximab treatment in colorectal cancer patients
}

\author{
M Scartozzi, , , I Bearzi ${ }^{2}$, A Mandolesi ${ }^{2}$, R Giampieri', L Faloppi', E Galizia ${ }^{3}$, F Loupakis ${ }^{4}$, A Zaniboni ${ }^{5}$, F Zorzi ${ }^{6}$, \\ T Biscotti ${ }^{2}$, Labianca $^{7}$, A Falcone ${ }^{4}$ and S Cascinu' \\ 'Department of Clinica di Oncologia Medica, AO Ospedali Riuniti-Università Politecnica delle Marche, Via Conca, 60020 Ancona, Italy; ${ }^{2}$ Department of \\ Anatomia Patologica, AO Ospedali Riuniti-Università Politecnica delle Marche, Ancona, Italy; ' ${ }^{3}$ eppartment of Oncologia Medica, Ospedale 'Profili', \\ Fabriano, Italy; ${ }^{4}$ Department of Oncologia Medica, Università degli Studi di Pisa, Pisa, Italy; ${ }^{5}$ Department of Oncologia Medica, Fondazione \\ Poliambulanza, Brescia, Italy; ${ }^{6}$ Department of Anatomia Patologica, Fondazione Poliambulanza, Brescia, Italy; ${ }^{7}$ Department of Oncologia Medica, \\ Ospedali Riuniti, Bergamo, Italy
}

BACKGROUND: Epidermal growth factor receptor (EGFR) promoter methylation may be responsible for the loss of EGFR expression in neoplastic cells. The primary aim of our study was to verify a possible correlation between EGFR gene promoter methylation and clinical outcome in metastatic colorectal cancer patients receiving chemotherapy with irinotecan and cetuximab.

METHODS: Colorectal samples from patients treated with irinotecan-cetuximab were analysed for EGFR promoter methylation and EGFR immunohistochemistry.

RESULTS: Fifty-two patients were analysed. Thirty patients (58\%) showed EGFR promoter hypermethylation. In EGFR promoter methylated and EGFR promoter unmethylated patients, we observed a partial response in 3 (I0\%) and 13 (59\%) patients, respectively $(P=0.03)$, progressive disease was obtained in $19(63 \%)$ and $2(9 \%)$ patients, respectively, with EGFR promoter methylated and EGFR promoter unmethylated tumours $(P=0.000 \mathrm{I})$. Median progression-free survival was 2.4 months in patients showing EGFR promoter methylated tumours and 7.4 months for those who had $E G F R$ promoter unmethylated tumours $(P<0.000$; Figure I). Median overall survival was 6.I months in patients showing EGFR promoter methylated tumours and 17.8 months for those who had EGFR promoter unmethylated tumours $(P<0.000$ I; Figure 2).

CONCLUSION: EGFR promoter hypermethylation, after confirmation in larger data set, may represent a valuable asset in further studies investigating EGFR as a therapeutic target in colorectal cancer.

British Journal of Cancer (201 I) 104, 1786-1790. doi:10.1038/bjc.201 I.161 www.bjcancer.com

Published online 10 May 2011

(C) 201 I Cancer Research UK

Keywords: EGFR promoter methylation; cetuximab; colorectal cancer

The molecular mechanisms underlying response or resistance of epidermal growth factor receptor (EGFR) overexpressing colorectal tumours to anti-EGFR compounds are still largely unknown. However, economic costs and toxicity risks deriving from the use of anti-EGFR therapeutic options made increasingly essential the identification of molecular or clinical predictive factors of response (or resistance) for a better, more accurate, actually targeted, selection of patients more likely to benefit from such a treatment approach. The main research areas in this setting have been focusing on the role of EGFR protein expression, EGFR gene amplification, EGFR mutations, and markers of EGFR downstream signalling (Moroni et al, 2005; Benvenuti et al, 2007; Scartozzi et al, 2007, 2009; Di Nicolantonio et al, 2008; Ng and Zhu, 2008; Loupakis et al, 2009; Perrone et al, 2009). Only after several years of intense translational research and clinical absence of predictive factors, the introduction of the K-RAS mutational status seemed to possess the necessary potential for a full translation into clinical practice of the concept of targeted therapy in this setting (Di Fiore et al, 2007; Lievre et al, 2008; Van Cutsem et al, 2009).

*Correspondence: Dr M Scartozzi; E-mail: marioscartozzi@libero.it Revised 29 March 2011; accepted 17 April 2011; published online 10 May $201 \mathrm{I}$
However, if on the one hand we are now able to exclude from anti-EGFR treatment patients with putative refractory colorectal tumours (i.e., those harbouring a K-RAS mutant status), on the other hand we are still incapable to accurately select responding patients among those without K-RAS mutations. In fact clinical observations suggested that a non-negligible proportion of patients, usually ranging from 40 to $70 \%$, does not seem to benefit from the use of anti-EGFR-targeted antibodies although in the absence of a mutation of the $K-R A S$ gene (i.e., K-RAS wild-type patients) (Di Fiore et al, 2007; Jonker et al, 2007; Van Cutsem et al, 2007, 2009; Lievre et al, 2008).

We now know that under normal circumstances, EGFR expression is primarily regulated by the abundance of its m-RNA (Scartozzi et al, 2007; Van Cutsem et al, 2009). This observation is of particular relevance if we consider that EGFR m-RNA expression demonstrated a possible correlation with survival during anti-EGFR treatment (Xu et al, 1984; Merlino et al, 1985; Vallböhmer et al, 2005). At least hypothetically, EGFR promoter silencing may then affect clinical outcome of patients treated with anti-EGFR strategies through the inhibition of EGFR m-RNA expression.

Cytosine methylation of promoter-associated $\mathrm{CpG}$ islands is an important epigenetic mechanism of gene silencing that is frequently observed in cancer, leading to inhibition of gene 


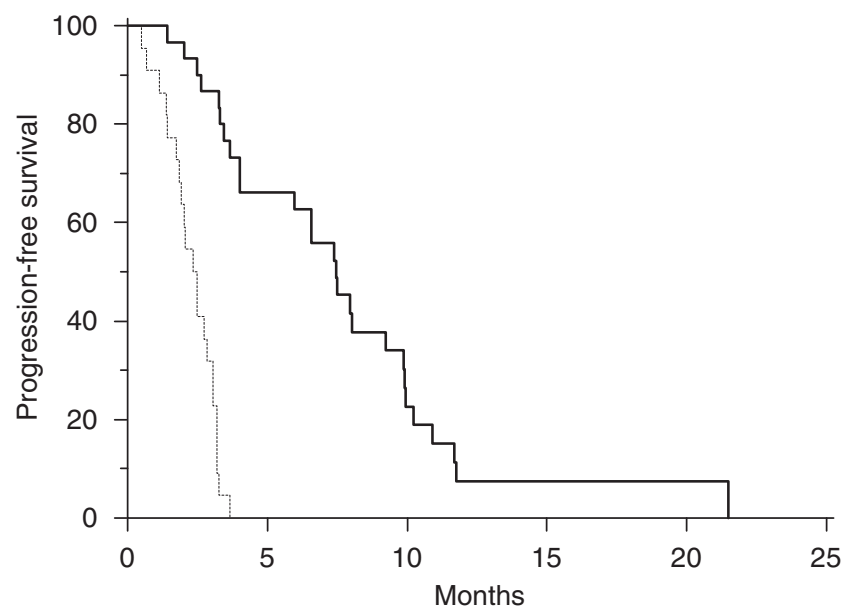

Figure I Kaplan-Meier curves for median progression-free survival (PFS) of colorectal cancer patients treated with irinotecan and cetuximab with EGFR promoter methylated (- $)$ and without EGFR promoter methylated (- $\longrightarrow$ ) tumours (2.4 vs 7.4 months, $P<0.000 \mathrm{I}$ ).

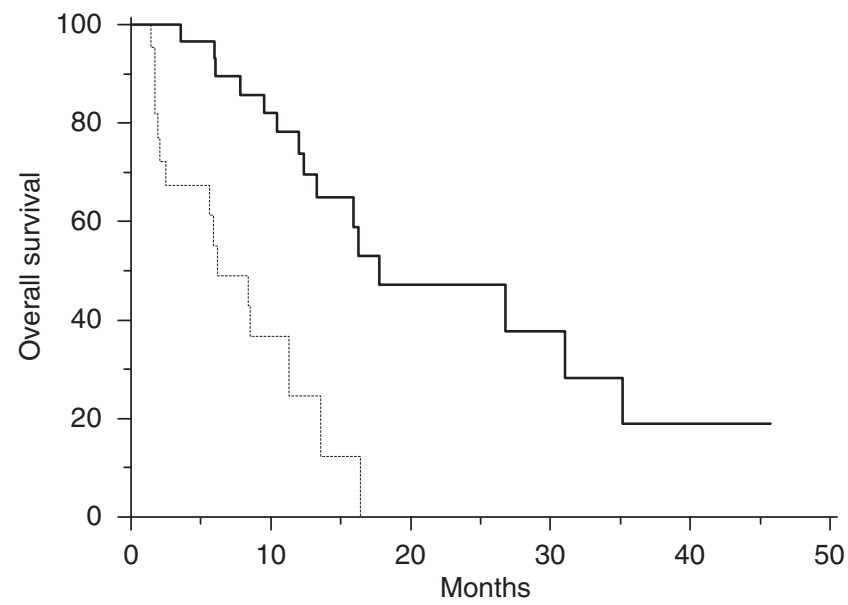

Figure 2 Kaplan-Meier curves for median overall survival (OS) of colorectal cancer patients treated with irinotecan and cetuximab with EGFR promoter methylated (-) and without EGFR promoter methylated (-) tumours (6.I vs 17.8 months, $P<0.000$ I).

transcription (Xu et al, 1984; Merlino et al, 1985). Hypermethylation typically affects tumour-suppressor genes, but can also silence oncogenes such as COX219 and TERT (Devereux et al, 1999; Santini et al, 2001; Jones and Baylin, 2002).

Montero et al analysed the presence of EGFR promoter hypermethylation in a series of cell lines and tissues, suggesting that EGFR promoter hypermethylation may represent a relevant event in breast, head and neck, and lung tumours. In this study, EGFR hypermethylation was observed in none of the 17 colorectal tumours tested and in 7 of the $17(24 \%)$ normal colon tissue (Montero et al, 2006). However, in a larger analysis including 63 colorectal tumours we previously demonstrated that EGFR promoter methylation should not be considered a rare event in colorectal tumours as this biological phenomenon occurred in as many as $39 \%$ of all cases analysed (Scartozzi et al, 2009).

Based on these considerations, we then hypothesised that EGFR promoter methylation may be responsible for the loss of EGFR expression in neoplastic cells, with the consequent loss of the therapeutic target for anti-EGFR monoclonal antibodies. These observations may be relevant for clinical outcome prediction with the use of anti-EGFR treatment strategies and could also indicate new research perspectives for the introduction of pharmacological agents able to determine re-expression of the therapeutic target (EGFR) in this area. The aim of our study was then to verify a possible correlation between EGFR gene promoter methylation and clinical outcome in metastatic colorectal cancer patients receiving chemotherapy with irinotecan and cetuximab. The possible correlation between EGFR promoter methylation status and EGFR protein expression was also tested.

\section{PATIENTS AND METHODS}

\section{Patients selection}

Patients with histologically proven EGFR-positive, K-RAS wildtype, metastatic, colorectal cancer receiving a combination of cetuximab and irinotecan after at least one line of previous chemotherapy were eligible for our analysis. To be eligible, patients must also have received an irinotecan-based chemotherapy regimen for at least 6 weeks and must have presented progression of disease during receipt of this regimen or within 3 months thereafter. All patients received cetuximab at an initial dose of $400 \mathrm{mg}$ per square metre followed by weekly infusions of $250 \mathrm{mg}$ per square metre. Irinotecan was administered at a dose of $180 \mathrm{mg}$ per square metre every 2 weeks either alone or in combination with five fluorouracil and leucovorin. Tumour response was evaluated every 8 weeks by clinicians' assessment and according to the Response Evaluation Criteria in Solid Tumours (RECIST).

Formalin-fixed and paraffin-embedded tumour samples (either primary site or metastasis or both when available) of colorectal cancer patients were analysed for EGFR protein expression (immunohistochemistry) and for EGFR promoter methylation.

\section{EGFR promoter methylation study}

Analysis of EGFR promoter methylation was performed following a DNA Extraction Protocol from paraffin-embedded tissue and a methylation-specific PCR (MSP). The tumour samples were processed according to the QIAamp DNA mini Tissue Protocol, using QIAamp DNA Mini Kit (QIAGEN GmbH, Hilden, Germany). Before PCR amplification, the DNA extract was treated with sodium bisulphite as described in the handbook of the 'EpiTect Bisulfite Kit' (QIAGEN GmbH). Bisulphite modification of DNA to convert all unmethylated cytosines to uracil and then to thymidine during the subsequent PCR step while leaving the methylated cytosines unaffected was performed as described by Herman et al (1996). For PCR amplification, two sets of primers were designed from nt -130 to -300 (relative to ATG) in the $5^{\prime}$-untranslated region of the human EGFR promoter.

The primer sequences used were $5^{\prime}$-TGTTTTGTTTTTTT GTGTTTTGGTTTGTGT- $3^{\prime}$ (sense) and 5'-CATCCAATCTAAACA ACAACAACCACCA-3' (antisense) for unmethylated DNA and $5^{\prime}$-TGTTTTTTCGCGTTTCGGTTCGCGC- ${ }^{\prime}$ (sense) and 5'-CGTCTAA ACGACGACGACCGCCG-3' (antisense) for methylated DNA, both of which amplify $\sim 150 \mathrm{bp}$ products (Nagothu et al, 2004). The PCR mixture contained $1 \times$ PCR buffer, Minus Mg; $0.2 \mathrm{~mm} \mathrm{dNTP}$ mixture (each); $1.5 \mathrm{mM} \mathrm{MgCl}_{2} ; 0.2 \mu \mathrm{M}$ Primer mix (each); 1.0 unit Platinum Taq DNA Polymerase (Invitrogen, Carlsbad, CA, USA); and bisulphite-modified DNA (of $1 \mathrm{ng}-2 \mu \mathrm{g}$ ) in a final volume of $50 \mu \mathrm{l}$. Controls without DNA were performed for each set of PCRs. Each PCR product $(30 \mu \mathrm{l})$ was directly visualised on $10 \%$ acrylamide gels. The gel was stained with ethidium bromide and photographed under UV illumination. An enzymatically methylated human male genomic DNA (CpGenome Universal Methylated DNA CHEMICON International) was used as a methylationpositive control for gene methylation studies and was processed as above mentioned. 


\section{Immunohistochemistry}

Epidermal growth factor receptor (DakoCytomation, Carpinteria, CA, USA) was evaluated with an immunohistochemistry technique on $5 \mu \mathrm{m}$-thick tissue section obtained from paraffin-embedded specimens fixed in $10 \%(\mathrm{v} / \mathrm{v})$ neutral buffered formalin, and was performed using kit EGFR PharmaDx (DakoCytomation) according to the manufacturer's instructions as previously described (Scartozzi et al, 2004). Briefly, the intensity of EGFR reactivity was scored using a three-tier system as follows: $1+$ (weak intensity: faint brown membranous staining); $2+$ (moderate intensity: brown membranous staining of intermediate darkness producing a complete or incomplete circular outline of the neoplastic cell); $3+$ (strong intensity: dark brown or black membranous staining producing a thick outline, complete or incomplete of the neoplastic cell) (Scartozzi et al, 2004).

\section{Statistical analysis}

Statistical analysis was performed with MedCalc package (MedCalc v9.4.2.0, MedCalc Software, Mariakerke, Belgium).

The association between categorical variables was analysed by $\chi^{2}$-test. Survival distribution was estimated by the Kaplan-Meier method. Significant differences in probability of relapsing between the strata were evaluated by log-rank test.

A significant level of 0.05 was chosen to assess the statistical significance.

For statistical analysis, overall survival (OS) and progressionfree survival (PFS) were defined, respectively, as the interval between the start of cetuximab and irinotecan therapy to death or last follow-up visit and as the interval between the start of cetuximab and irinotecan therapy to clinical progression or death or last follow-up visit if not progressed.

\section{RESULTS}

Fifty-two metastatic colorectal cancer patients were eligible for our analysis: 33 patients were males (63\%) and 19 females (37\%), median age at diagnosis was 62 years (range 35-80) (Table 1).

In 27 patients (52\%), the EGFR promoter methylation study was conducted on primary colorectal tumours, in 21 cases (40\%) both primary tumours and corresponding metastasis (liver metastases in all cases) were available for analysis, while in 4 cases (8\%) only the metastatic site (liver metastases in all cases) was investigated. For study purposes when results for EGFR methylation status in primary colorectal tumours and corresponding metastases resulted conflicting, only the methylation status in metastases was considered biologically relevant. Although data guiding this choice are lacking the purpose of the study was to assess the correlation between EGFR gene promoter methylation and clinical outcome in patients treated with cetuximab for metastatic disease. Therefore, we can hypothesise that the methylation status in metastases is more relevant for response/resistance to such treatment approach.

Globally, 30 patients (58\%) showed EGFR promoter hypermethylation either in primary colorectal cancer or in metastasis. In 12 cases (40\%), EGFR promoter methylation resulted biallelic, whereas in the remaining 18 tumours $(60 \%)$ only one allele resulted methylated. This two groups of patients (i.e., those with monoallelic EGFR promoter methylation and those with monoallelic EGFR promoter methylation resulted) comparable for all main clinical characteristics and experienced a similar clinical outcome during treatment with cetuximab (Table 2). Among the 21 patients in whom both primary site and metastases were available for $E G F R$ methylation study, EGFR methylation status of primary tumour was in accordance with that of metastasis in 16 patients (76\%): 4 patients with EGFR promoter hypermethylation and 12 patients with unmethylated tumours. In the remaining five patients (24\%), there was not concordance in EGFR promoter methylation
Table I Patients characteristics and main study results

\begin{tabular}{|c|c|c|c|c|}
\hline & $\begin{array}{l}\text { Whole } \\
\text { group } \\
(n=52)\end{array}$ & $\begin{array}{c}\text { EGFR } \\
\text { unmet } \\
(n=22,42 \%)\end{array}$ & $\begin{array}{c}\text { EGFR } \\
\text { met } \\
(n=30,58 \%)\end{array}$ & $P$-value \\
\hline Age (range) & $62(35-80)$ & $63(35-78)$ & $62(37-80)$ & \\
\hline \multicolumn{5}{|l|}{$\operatorname{Sex}$} \\
\hline Males & 33 (63\%) & $15(68 \%)$ & $18(66 \%)$ & \\
\hline Females & $19(37 \%)$ & 7 (32\%) & $12(34 \%)$ & \\
\hline \multicolumn{5}{|l|}{ Previous lines of treatment } \\
\hline I & $6(12 \%)$ & $4(18 \%)$ & $2(7 \%)$ & \\
\hline $2-3$ & $46(88 \%)$ & $18(82 \%)$ & $28(93 \%)$ & \\
\hline \multicolumn{5}{|l|}{ Treatment } \\
\hline mFOLFIRI+cetuximab & $18(35 \%)$ & $8(36 \%)$ & $10(33 \%)$ & \\
\hline Irinotecan+cetuximab & $34(65 \%)$ & $14(68 \%)$ & $20(67 \%)$ & \\
\hline \multicolumn{5}{|l|}{ Response rate } \\
\hline PR & $16(31 \%)$ & $13(59 \%)$ & $3(10 \%)$ & 0.03 \\
\hline SD & $15(29 \%)$ & $7(32 \%)$ & $8(27 \%)$ & \\
\hline PD & $21(40 \%)$ & $2(9 \%)$ & $19(63 \%)$ & 0.0001 \\
\hline Median PFS (months) & 3.2 & 7.4 & 2.4 & $<0.0001$ \\
\hline Median OS (months) & 13.3 & 17.8 & 6.1 & $<0.0001$ \\
\hline
\end{tabular}

Abbreviations: $\mathrm{mFOLFIRI}=$ modified FOLFIRI (irinotecan $180 \mathrm{mg} \mathrm{sqm}^{-1} \mathrm{dl}, 5 \mathrm{FU}$ bolus $400 \mathrm{mg} \mathrm{sqm}^{-1} \mathrm{dl}$, 5FU $2400 \mathrm{mg} \mathrm{sqm}^{-1}$ continuous infusion for $46 \mathrm{~h}$ ); $\mathrm{PR}=$ partial remission; $\mathrm{SD}=$ stable disease; $\mathrm{PD}=$ progressive disease; $\mathrm{PFS}=$ progres sion-free survival; $O S=$ overall survival; $E G F R=$ epidermal growth factor receptor. Only statistically significant $P$-values have been indicated.

Table 2 Patients characteristics and main results according to EGFR promoter methylation status (monoallelic vs biallelic EGFR promoter methylation)

\begin{tabular}{|c|c|c|c|}
\hline & $\begin{array}{c}\text { EGFR } \\
\text { monoallelic } \\
(n=18,60 \%)\end{array}$ & $\begin{array}{c}\text { EGFR } \\
\text { biallelic } \\
(n=12,40 \%)\end{array}$ & $P$-value \\
\hline Age (range) & $61(35-78)$ & $62(37-80)$ & \\
\hline \multicolumn{4}{|l|}{ Sex } \\
\hline Males & 11 (61\%) & 7 (58\%) & \\
\hline Females & $7(39 \%)$ & $5(42 \%)$ & \\
\hline \multicolumn{4}{|l|}{ Previous lines of treatment } \\
\hline 1 & | (5\%) & । (8\%) & \\
\hline $2-3$ & $17(95 \%)$ & $11(92 \%)$ & \\
\hline \multicolumn{4}{|l|}{ Treatment } \\
\hline mFOLFIRI+cetuximab & $6(33 \%)$ & $4(33 \%)$ & \\
\hline Irinotecan+cetuximab & $12(66 \%)$ & $8(66 \%)$ & \\
\hline \multicolumn{4}{|l|}{ Response rate } \\
\hline PR & $2(11 \%)$ & I (8\%) & Ns \\
\hline SD & $5(28 \%)$ & $3(25 \%)$ & Ns \\
\hline PD & $11(61 \%)$ & $8(67 \%)$ & Ns \\
\hline Median PFS (months) & 2.2 & 2.4 & Ns \\
\hline Median OS (months) & 5.9 & 6.1 & Ns \\
\hline
\end{tabular}

Abbreviations: $\mathrm{mFOLFIRI}=$ modified FOLFIRI (irinotecan $180 \mathrm{mg} \mathrm{sqm}^{-1} \mathrm{dI}, 5 \mathrm{FU}$ bolus $400 \mathrm{mgsqm}^{-1} \mathrm{dl}, 5 \mathrm{FU} 2400 \mathrm{mgsqm}^{-1}$ continuous infusion for $46 \mathrm{~h}$ ); $\mathrm{PR}=$ partial remission; $\mathrm{SD}=$ stable disease; $\mathrm{PD}=$ progressive disease; $\mathrm{PFS}=$ progression-free survival; $O S=$ overall survival; $E G F R=$ epidermal growth factor receptor. No statistically significant differences could be noticed among the two groups of patients.

status between primary tumour and metastasis. In particular, two patients with EGFR hypermethylation in the primary tumour showed unmethylated EGFR in metastasis and three metastases showing EGFR promoter hypermethylation derived from unmethylated EGFR primary tumours. 
All major clinical characteristics resulted comparable among EGFR promoter methylated and EGFR promoter unmethylated groups of patients. In particular, no differences were noticed for sex, age at diagnosis, and previous lines of chemotherapy (Table 1). On the contrary in EGFR promoter methylated and EGFR promoter unmethylated patients, we observed a partial response in $3(10 \%)$ and $13(59 \%)$ patients, respectively $(P=0.03)$, progressive disease was obtained in $19(63 \%)$ and $2(9 \%)$ patients, respectively, with EGFR promoter methylated and EGFR promoter unmethylated tumours $(P=0.0001)$. No statistically significant differences were noticed for stable disease (Table 1). Median PFS was 2.4 months in patients showing EGFR promoter methylated tumours and 7.4 months for those who had EGFR promoter unmethylated tumours $(P<0.0001$; Figure 1). Median OS was 6.1 months in patients showing EGFR promoter methylated tumours and 17.8 months for those who had EGFR promoter unmethylated tumours $(P<0.0001$; Figure 2$)$.

Overall, EGFR immunohistochemical assessment resulted positive in 36 patients $(69 \%)$

Lack of EGFR protein expression was observed in nine EGFR promoter methylated tumours (30\%) and in seven EGFR promoter unmethylated tumours (32\%).

\section{DISCUSSION}

The expanding role of anti-EGFR therapeutic modalities for the treatment of colorectal cancer patients, along with the growing number of cases potentially requiring such a treatment approach, made the need for a correct and reliable identification of responding tumours increasingly crucial.

Unfortunately beside K-RAS mutational status and although the intense ongoing translational research no clear indications for further predictive molecular markers are available at the moment.

Transcriptional silencing of tumour-suppressor genes, by methylation of $\mathrm{CpG}$ dinucleotide-rich areas in gene promoter, is one of the major epigenetic mechanisms leading to inactivation (and thus to lack of m-RNA expression) of important growth control genes (Herman and Baylin, 2003). However, data about EGFR gene silencing by promoter methylation are substantially lacking and may help clarifying the role of this epigenetic mechanism on colorectal cancer biology (Scartozzi et al, 2009). The implications for anti-EGFR treatment options are also relevant. Loss of EGFR expression consequent to promoter methylation may underlie loss of the therapeutic target and may then indicate both a predictive factor for anti-EGFR therapy and new research perspectives for the use of demethylating agents.

In our analysis, EGFR promoter methylation was evident in 30 patients $(58 \%)$, thus indicating that this biological phenomenon should not be considered an infrequent event in colorectal tumours and confirming our previous report. Moreover, patients presenting an EGFR promoter methylated tumour experienced in fact a worse clinical outcome thus confirming our hypothesis of a role for EGFR promoter methylation in determining the efficacy of anti-EGFR-targeted monoclonal antibodies.

A clear correspondence between EGFR promoter methylation and loss of EGFR immunohistochemical expression was not evident. It is then unlikely that loss of EGFR expression as determined with immunohistochemistry may be related to EGFR promoter hypermethylation. When we consider that EGFR promoter methylation represents a predictive factor for cetuximab treatment in our series, the observation of a lack of concordance of this biological phenomenon with EGFR immunohistochemistry expression seems clinically sound and in accordance to previous data, indicating that loss of EGFR immunohistochemical expression should not be considered a predictive factor for anti-EGFR monoclonal antibodies activity (Cunningham et al, 2004). However, it is also likely that immunohistochemistry evaluation of EGFR protein expression may not be accurate enough to detect loss of EGFR protein in cancer tissues, thus compromising data analysis and interpretation in this setting (Atkins et al, 2004).

It is also important to note that only in 12 patients (40\%) EGFR methylation resulted biallelic, and methylation of only one allele could not be sufficient to actually silence the gene, inducing a total loss of protein production. On the other hand, EGFR promoter methylation of one allele seemed able to determine resistance to anti-EGFR therapy in our series and we could not find substantial difference among the two groups of patients with EGFR promoter methylation (i.e., those with monoallelic EGFR promoter methylation and those with monoallelic EGFR promoter methylation). Therefore, we can speculate that other relevant biological mechanisms, such as loss of heterozygosity, may contribute to loss of gene function along with monoallelic promoter methylation in tumour tissues.

However, the relatively small number of patients analysed in our series represents a clear limitation for a definitive conclusion about the role of EGFR promoter methylation in determining response to anti-EGFR treatments, and our findings should be considered speculative. A further possible limiting factor is represented by the proportion of patients with a concordant $E G F R$ methylation status between primary tumour and metastases (76\%). This observation is however in line with our previous observation of a concordance for EGFR methylation status in $69 \%$ of patients with metastatic colorectal cancer.

The possible role of EGFR promoter methylation in EGFR gene silencing could provide new clues in anti-EGFR biological agents use optimisation. It has been in fact reported that treatment with the demethylating agent decitabine may result in the re-expression of EGFR in two breast cancer cell lines, in which EGFR transcription was abolished by EGFR promoter hypermethylation. Both cell lines are relatively resistant to killing by the EGFR inhibitor gefitinib; however, after co-treatment with decitabine and gefitinib, a significant effect on the induction of apoptosis was observed (Montero et al, 2006).

Combined approaches targeting EGFR dysfunction may be useful for patients with EGFR methylated tumours and could represent the basis for prospective studies aiming to compare clinical response with EGFR directed therapeutic agents. Strategies have been developed that combine treatments with drugs reactivating silenced gene expression (such as demethylating drugs) with secondary agents that target the re-expressed genes and/or reconstituted signal transduction pathways (Karpf and Jones, 2002). This treatment approach looks appealing for further dedicated trials in EGFR promoter methylated tumours.

We believe that EGFR promoter hypermethylation, after confirmation in larger data set, may represent a valuable and important asset to be considered in further studies investigating the role of EGFR as a therapeutic target in colorectal cancer patients.

\section{REFERENCES}

Atkins D, Reiffen KA, Tegtmeier CL, Winther H, Bonato MS, Störkel S (2004) Immunohistochemical detection of EGFR in paraffin-embedded tumor tissues: variation in staining intensity due to choice of fixative and storage time of tissue sections. Histochem Cytochem 52: 893-901
Benvenuti S, Sartore-Bianchi A, Di Nicolantonio F, Zanon C, Moroni M, Veronese S, Siena S, Bardelli A (2007) Oncogenetic activation of RAS/RAF signaling pathway impairs the response of metastatic colorectal cancers to anti-epidermal growth factor receptor antibody therapies. Cancer Res 67: 2643-2648 
Cunningham D, Humblet Y, Siena S, Khayat D, Bleiberg H, Santoro A, Bets D, Mueser M, Harstrick A, Verslype C, Chau I, Van Cutsem E (2004) Cetuximab monotherapy and cetuximab plus irinotecan in irinotecanrefractory metastatic colorectal cancer. $N$ Engl J Med 351: 337-345

Devereux TR, Horikawa I, Anna CH, Annab LA, Afshari CA, Barrett JC (1999) DNA methylation analysis of the promoter region of the human telomerase reverse transcriptase (hTERT) gene. Cancer Res 59: $6087-6090$

Di Fiore F, Blanchard F, Charbonnier F, Le Pessot F, Lamy A, Galais MP, Bastit L, Killian A, Sesboüé R, Tuech JJ, Queuniet AM, Paillot B, Sabourin JC, Michot F, Michel P, Frebourg T (2007) Clinical relevance of KRAS mutation detection in metastatic colorectal cancer treated by cetuximab plus chemotherapy. Br J Cancer 96: 1166-1169

Di Nicolantonio F, Martini M, Molinari F, Sartore-Bianchi A, Arena S, Saletti P, De Dosso S, Mazzucchelli L, Frattini M, Siena S, Bardelli A (2008) Wild-type BRAF is required for response to panitumumab or cetuximab in metastatic colorectal cancer. J Clin Oncol 26: 5705-5712

Herman JG, Baylin SB (2003) Gene silencing in cancer in association with promoter hypermethylation. $N$ Engl J Med 349: $2042-2054$

Herman JG, Graff JR, Myöhänen S, Nelkin BD, Baylin SB (1996) Methylation-specific PCR: a novel PCR assay for methylation status of CpG islands. Proc Natl Acad Sci USA 93: 9821 -9826

Jones PA, Baylin SB (2002) The fundamental role of epigenetic events in cancer. Nat Rev Genet 3: $415-428$

Jonker DJ, O'Callaghan CJ, Karapetis CS, Zalcberg JR, Tu D, Au HJ, Berry SR, Krahn M, Price T, Simes RJ, Tebbutt NC, van Hazel G, Wierzbicki R, Langer C, Moore MJ (2007) Cetuximab for the treatment of colorectal cancer. J Clin Oncol 357: 2040-2047

Karpf AR, Jones DA (2002) Reactivating the expression of methylation silenced genes in human cancer. Oncogene 21: 5496-5503

Lievre A, Bachet JB, Boige V, Cayre A, Le Corre D, Buc E, Ychou M, Bouché O, Landi B, Louvet C, André T, Bibeau F, Diebold MD, Rougier P, Ducreux M, Tomasic G, Emile JF, Penault-Llorca F, Laurent-Puig P (2008) Kras mutation as an independent prognostic factor in patients with advanced colorectal cancer treated with cetuximab. J Clin Oncol 28: $374-379$

Loupakis F, Pollina L, Stasi I, Ruzzo A, Scartozzi M, Santini D, Masi G, Graziano F, Cremolini C, Rulli E, Canestrari E, Funel N, Schiavon G, Petrini I, Magnani M, Tonini G, Campani D, Floriani I, Cascinu S, Falcone A (2009) PTEN expression and KRAS mutations on primary tumors and metastases in the prediction of benefit from cetuximab plus irinotecan for patients with metastatic colorectal cancer. J Clin Oncol 27: $2622-2629$

Merlino GT, Ishii S, Whang-Peng J, Knutsen T, Xu YH, Clark AJ, Stratton RH, Wilson RK, Ma DP, Roe BA, Hunts JH, Shimizu N, Pastan I (1985) Structure and localization of genes encoding aberrant and normal epidermal growth factor receptor RNAs from A431 human carcinoma cells. Mol Cell Biol 5: 1722-1734

Montero AJ, Marcela Díaz-Montero C, Mao L, Youssef EM, Estecio M, Shen L, Issa JP (2006) Epigenetic inactivation of EGFR by CpG island hypermethylation in cancer. Cancer Biol Ther 5: 1494-1501

Moroni M, Veronese S, Benvenuti S, Marrapese G, Sartore-Bianchi A, Di Nicolantonio F, Gambacorta M, Siena S, Bardelli A (2005) Gene copy number for epidermal growth factor receptor (EGFR) and clinical response to anti EGFR treatment in colorectal cancer: a cohort study. Lancet Oncol 6: 279-286
Nagothu KK, Rishi AK, Jaszewski R, Kucuk O, Majumdar AP (2004) Folic acid- mediated inhibition of serum-induced activation of EGFR promoter in colon cancer cells. Am J Physiol Gastrointestinal Liver Physiol 287: $541-546$

Ng K, Zhu AX (2008) Targeting the epidermal growth factor receptor in metastatic colorectal cancer. Crit Rev Oncol/Hematol 65: 8-20

Perrone F, Lampis A, Orsenigo M, Di Bartolomeo M, Gevorgyan A, Losa M, Frattini M, Riva C, Andreola S, Bajetta E, Bertario L, Leo E, Pierotti MA, Pilotti S (2009) PI3KCA/PTEN deregulation contributes to impaired responses to cetuximab in metastatic colorectal cancer patients. Ann Oncol 20: $84-90$

Santini V, Kantarjian HM, Issa JP (2001) Changes in DNA methylation in neoplasia: pathophysiology and therapeutic implications. Ann Intern Med 134: 573 - 586

Scartozzi M, Bearzi I, Berardi R, Mandolesi A, Fabris G, Cascinu S (2004) Epidermal growth factor receptor (EGFR) status in primary colorectal tumors does not correlate with EGFR expression in related metastatic sites: implications for treatment with EGFR-targeted monoclonal antibodies. J Clin Oncol 22: $4772-4778$

Scartozzi M, Bearzi I, Pierantoni C, Mandolesi A, Loupakis F, Zaniboni A, Catalano V, Quadri A, Zorzi F, Berardi R, Biscotti T, Labianca R, Falcone A, Cascinu S (2007) Nuclear factor-kB tumor expression predicts response and survival in irinotecan-refractory metastatic colorectal cancer treated with cetuximab-irinotecan therapy. J Clin Oncol 25: $3930-3935$

Scartozzi M, Bearzi I, Mandolesi A, Pierantoni C, Loupakis F, Zaniboni A, Negri F, Quadri A, Zorzi F, Galizia E, Berardi R, Biscotti T, Labianca R, Masi G, Falcone A, Cascinu S (2009) Epidermal growth factor receptor (EGFR) gene copy number (GCN) correlates with clinical activity of irinotecan-cetuximab in K-RAS wild-type colorectal cancer: a fluorescence in situ (FISH) and chromogenic in situ hybridization (CISH) analysis. BMC 9: 303-310

Scartozzi M, Bearzi I, Mandolesi A, Galizia E, Pierantoni C, Loupakis F, Berardi R, Zaniboni A, Quadri A, Zorzi F, Biagetti S, Loretelli C, Biscotti T, Labianca R, Masi G, Falcone A, Cascinu S (2009) Epidermal growth factor receptor gene promoter methylation in primary colorectal tumors and corresponding metastatic sites: a new perspective for an 'old' therapeutic target. Anal Quant Cytol Histol 31: 417-423

Vallböhmer D, Zhang W, Gordon M, Yang DY, Yun J, Press OA, Rhodes $\mathrm{KE}$, Sherrod AE, Iqbal S, Danenberg KD, Groshen S, Lenz HJ (2005) Molecular determinants of cetuximab efficacy. J Clin Oncol 23: $3536-3544$

Van Cutsem E, Kohne CH, Hitre E, Zaluski J, Chang Chien CR, Makhson A, D'Haens G, Pintér T, Lim R, Bodoky G, Roh JK, Folprecht G, Ruff P, Stroh C, Tejpar S, Schlichting M, Nippgen J, Rougier P (2009) Cetuximab and chemotherapy as initial treatment for metastatic colorectal cancer. $N$ Engl J Med 360: 1408 - 1417

Van Cutsem E, Peeters M, Siena S, Humblet Y, Hendlisz A, Neyns B, Canon JL, Van Laethem JL, Maurel J, Richardson G, Wolf M, Amado RG (2007) Open-label phase III trial of panitumumab plus best supportive care compared with best supportive care alone in patients with chemotherapy-refractory metastatic colorectal cancer. J Clin Oncol 25 $1658-1664$

Xu YH, Richert N, Ito S, Merlino GT, Pastan I (1984) Characterization of epidermal growth factor receptor gene expression in malignant and normal human cell lines. Proc Natl Acad Sci USA 81: 7308-7312 